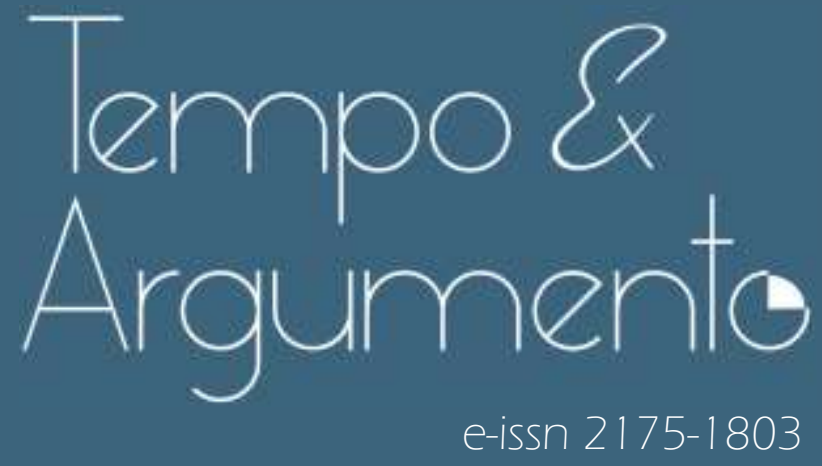

\title{
Entre livros e memórias: a web como lugar de nostalgia do Círculo do Livro
}

- Susana Azevedo Reis

Doutoranda em Comunicação na Universidade Federal de Juiz de Fora (UFJF). Juiz de Fora, MG - BRASIL lattes.cnpq.br/2479733794128062 susanareis.academico@gmail.com

(D) orcid.org/0000-0002-0162-0012

\section{- Christina Ferraz Musse}

Doutora em Comunicação Social pela Universidade Federal do Rio de Janeiro (UFRJ).

Professora da Universidade Federal de Juiz de Fora (UFJF).

Juiz de Fora, MG - BRASIL

lattes.cnpq.br/5736151077996505

cferrazmusse@gmail.com

(D) orcid.org/0000-0002-1172-5993

Para citar este artigo:

REIS, Susana Azevedo; MUSSE, Christina Ferraz. Entre livros e memórias: a web como lugar de nostalgia do Círculo do Livro. Tempo e Argumento, Florianópolis,

v. 13, n. 34, e0205, set./dez. 2021.

doi http://dx.doi.org/10.5965/2175180313342021e0205

Recebido: 29/05/2021

Aprovado: 04/11/2021 


\title{
Entre livros e memórias: a web como lugar de nostalgia do círculo do Livro
}

\begin{abstract}
Resumo
Este trabalho possui como objetivo compreender os rastros de memória do Círculo do Livro na web. Esse clube de assinatura de livros funcionou de 1973 até o final da década de 1990, chegando a possuir 800 mil associados. Contemporaneamente, no espaço digital, ex-assinantes e interessados no Círculo do Livro compartilham lembranças e experiências, criando um espaço fomentado por memórias individuais e coletivas. Acreditamos, assim, que blogs, sites e redes sociais apresentam um potencial para se caracterizarem como "lugares de memória" desse clube de livros, nos baseando no conceito de Pierre Nora (1993). Para refletirmos sobre o tema, iremos recorrer a autores que discutem questões sobre memória, história e nostalgia, como o próprio Pierre Nora (1993), Andreas Huyssen (2000), Michael Pollak (1989), Maurice Halbwachs (1990) Svetlana Boym (2017) e Katharina Niemeyer (2019). Como metodologia, realizaremos um levantamento dos resultados da palavra-chave Círculo do Livro no site de busca on-line Google e utilizaremos a metodologia de Análise de Conteúdo, de Laurence Bardin (2011), para compreender quais as principais narrativas memorialísticas e nostálgicas presentes nos artigos selecionados e nos respectivos comentários em cada publicação. Acreditamos que, além de ser um lugar de memória, os espaços de discussão sobre o Círculo do Livro no meio digital possuem também o potencial de serem "lugares de nostalgia", pois a memória ali compartilhada é repleta de saudade e afeto.
\end{abstract}

Palavras-chave: memória; lugar de nostalgia; web; digital; clubes de livros.

\section{Between books and memories: the web as a place of nostalgia for the Círculo do Livro}

\begin{abstract}
This work aims to understand the memory tracks of the Círculo do Livro on the web. This books sales club operated from 1973 to late 1990s, reaching 800 thousand members. Nowadays, in the digital space, former subscribers and interested people share memories and experiences, creating a space instigated by individual and collective memories. We believe, therefore, that blogs, websites and social networks have the potential to be characterized as "places of memory" for this book club, based on the concept of Pierre Nora (1993). To reflect on the theme, we will turn to authors who discuss concepts of memory, history and nostalgia, such Pierre Nora (1993), Andreas Huyssen (2000), Michael Pollak (1989), Maurice Halbwachs (1990) Svetlana Boym (2017) and Katharina Niemeyer (2019). As a methodology, we will carry out a survey of the results of the keyword Círculo do Livro on the online search site Google and we will use the methodology of Content Analysis, by Laurence Bardin (2011), to understand which are the main memorialistic and nostalgic narratives present in the selected articles and in the respective comments in each publication. We believe that, in addition to being a place of memory, the spaces for discussion about the Círculo do Livro in the digital environment also have the potential to be "places of nostalgia", as the memory shared there is full of nostalgia and affection.
\end{abstract}

Keywords: memory; place of nostalgia; web; digital; book clubs. 


\section{Círculo do Livro: um clube do livro que fez e ainda faz história}

Desde os primórdios, o ser humano utiliza-se de algum meio para conseguir se comunicar e ler boas histórias. Como comenta Alberto Manguel (1997), as antigas civilizações utilizaram-se de diversos meios para se expressar, criando plataformas similares aos livros: blocos em diversos formatos, folhetos de papiro, códices de pergaminho. No século XVI, em 1440, John Gutemberg criou a tecnologia que mudaria a forma como os livros eram confeccionados: a imprensa. Comparado à forma anterior de produção, a cópia escrita, os livros começaram a ser produzidos de forma um pouco mais ágil, com uniformidade de texto e um preço relativamente barato, o que contribuiu para a popularização da leitura.

Primeiramente, os livros se constituíram como uma ferramenta de disseminação da cultura cristã. Depois, começaram a aparecer as gramáticas e dicionários, que se consolidaram como ferramentas de estudo, em sua maior parte lidos pela aristocracia intelectual. Ainda nesse século, os romances e novelas também se popularizavam cada vez mais, através de peças de teatro e contos de cavaleiros. Nos séculos XVII e XVIII, os livros já eram encontrados em bibliotecas públicas ou particulares e, no século seguinte, iniciou-se a produção de obras menores e mais leves, para viagens. Segundo Manguel, com o tempo, os livros alcançaram um importante papel social, criando comunidades. Os clubes de leitura, ou clubes de livros, reforçam essa cultura grupal, reunindo integrantes para discutir sobre as obras escolhidas e seu contexto histórico e cultural. Para Roger Chartier (1999), essa prática se iniciou no século XVIII, com os books clubs. Eram sociedades de leitura com o objetivo de discutir e emprestar livros, disseminando a leitura entre os participantes. Assim, durante os séculos, indivíduos se reuniam em grupos, sociedades e clubes para ler, discutir e emprestar livros.

Dentro desse contexto, podemos encontrar dois tipos de clubes de livros, como comenta a pesquisadora Débora Bacega (2019). Primeiramente, existem clubes nos quais os leitores se reúnem e escolhem títulos a partir de uma biblioteca, sem custo. Por outro lado, existem os clubes de assinatura de livros. Nesse modelo, que se estabelece no âmbito do consumo, o leitor se filia ao clube, 
tornando-se um sócio, e a empresa se apresenta como um curador, escolhendo o título a ser lido. Dessa forma, o leitor custeia o volume e, na maioria das vezes, a organização das reuniões para a discussão da obra.

Atualmente, ainda é possível encontrar os dois tipos de clubes de livros. E as novas tecnologias permitem que os leitores se reúnam com ainda mais facilidade, através de salas virtuais de bate-papo e redes sociais. Além disso, ficou ainda mais fácil ser membro de um clube de assinatura. Com apenas um clique e de forma bem cômoda, o leitor paga periodicamente para receber os livros em casa.

Um dos primeiros clubes de livro nesse formato foi criado em 1926, nos Estados Unidos. O Book of the Month enviava livros pelos correios para os seus assinantes (BACEGA, 2019). No Brasil, o historiador Laurence Hallewel (2017) destaca que o primeiro clube do livro surgiu em 1941 e foi criado por Mário de Andrade, Cândido Portinari e Aníbal Machado, se estabelecendo como um clube de poesia. No ano seguinte, foi criado o clube Sociedade dos Cem Bibliógrafos do Brasil, que publicou para os seus associados 23 títulos até o seu encerramento, em 1968.

Em janeiro de 1943, foi criado por Mário Graciotti o Clube do Livro, que se baseava em três princípios "texto limpo e anotado, preço barato, entrega em domicílio" (HALLEWEL, 2017, p. 548). Ainda na década de 1940, foram criados os clubes O Livro do Mês e o Círculo Literário. Mas foi em março de 1973, que surgiu um dos mais longevos clubes de assinatura de livros no Brasil: o Círculo do Livro.

A propriedade do negócio era dividida entre a bem-sucedida empresa alemã Bertelsmann, que ocupava a posição de segunda maior organização editorial do mundo (HALLEWELL, 2017), que tinha 51\% da companhia, e a editora Abril, com 49\%. Como explica o ex-editor do Círculo, Fernando Nuno (2021), para ser associado ao clube, o leitor deveria pagar uma taxa de inscrição e escolher um livro recomendado pela publicação Revista do Livro, pertencente ao Círculo. Inicialmente, o cliente era obrigado a encomendar, pelo menos, dois livros a cada trimestre, para continuar afiliado (BACEGA, 2019). Porém, durantes as três décadas de funcionamento do Círculo, a quantidade de livros e o período de escolha foram se modificando. Em 1988, por exemplo, o associado deveria 
escolher um livro por bimestre. Esse envio era realizado por meio dos correios, para regiões longínquas como o Acre, ou um por um funcionário que entregava pessoalmente o livro (NUNO, 2021).

Segundo Hallewel (2017), o grande diferencial do Círculo do Livro era oferecer aos seus assinantes produtos de qualidade a um preço abaixo do mercado. Na década de 1980, o clube já possuía mais de 800 mil assinantes, chegando a 1 milhão, durante alguns meses (NUNO, 2021). Mas, ainda nessa década, o Brasil enfrentou uma crise econômica e as vendas de livros diminuíram, enquanto as despesas aumentaram. Assim, a Bertelsmann vendeu suas ações para a Abril (HALLEWEL, 2017), que manteve suas atividades como clube do livro até 1996. Porém, a Abril continuou a utilizar o nome Círculo do Livro em outras atividades editorais até o ano 2000 (NUNO, 2021).

Dessa forma, nos deparamos, nos dias de hoje, com certa dificuldade em encontrar informações oficiais sobre o Círculo do Livro em artigos e pesquisas acadêmicas. Ao mesmo tempo, o meio digital oferece um espaço para o compartilhamento de experiências e lembranças do Círculo, na maioria das vezes, com informações trazidas por ex-assinantes e o ex-editor Fernando Nuno, que ficou à frente do clube por 17 anos.

Por isso, esse trabalho propõe analisar como a web se tornou um espaço para a difusão das memórias individuais, coletivas e nostálgicas do círculo do Livro, com enfoque para as publicações realizadas em blogs e sites. Desejamos compreender quais as principais reflexões, lembranças e memórias que surgem em ex-assinantes a partir do compartilhamento de informações sobre este clube do livro.

Os conceitos relacionados à História e à Memória e suas problemáticas

A internet, ou como também é denominada, a web, se tornou um importante meio comunicacional e midiático, grande parte pelo seu potencial democrático, como comenta o historiador Carlo Ginzburg (2012). Dentro desse complexo espaço, podemos encontrar diversos rastros de memória e vestígios 
da história. Mas será que podemos confiar em todas as informações que encontramos? É sabido, segundo Ginzburg, que nem todas as informações postadas e compartilhadas podem ser consideradas verdadeiras e sem erros. É necessário separar o joio do trigo, afinal, na internet, podemos encontrar "falsidades, lixo, infâmias, misturadas com autênticas joias, informações preciosas, obras-primas em versão integral disponíveis para qualquer um, misturadas com puro lixo. Como aprendemos a escolher as joias no meio de todo o lixo?" (GINZBURG, 2012).

Para o pesquisador italiano é esse o grande desafio do historiador: compreender as especificidades dos registros e rastros na web para compreender o passado, ou mesmo o presente e as perspectivas de futuro. Ao mesmo tempo, para Roger Chartier (2007), a internet se tornou um local em que o leitor de um livro histórico, por exemplo, encontra os três dispositivos clássicos da prova da história: nota, referência e citação. Se, antes, era necessário consultar as referências bibliográficas e confirmar outras informações da obra em livros raros, que permaneciam em bibliotecas, e que geralmente não poderiam ser lidos, hoje, o leitor "é colocado em posição de poder ler, por sua vez, os livros que o historiador leu e consultar por si mesmo, diretamente, os documentos analisados" (CHARTIER, 2007, p. 60).

Já Andreas Huyssen (2000) nos lembra que ambas as memórias, cultural e pessoal, são afetadas por uma nova estrutura de temporalidade, que é gerada por um ritmo cada vez mais rápido da vida material e da aceleração de informações e imagens pela mídia. “A velocidade destrói o espaço e apaga a distância temporal. [...] Quanto mais a memória é armazenada em bancos de dados, mais o passado é sugado para a órbita do presente, pronto para ser acessado nas telas" (HUYSSEN, 2000, p. 74). A percepção da distância espacial e temporal está se apagando e os sujeitos estão se dissolvendo no mundo imaginário da tela cada vez mais.

Pensando ainda sobre as modificações da memória na sociedade, Pierre Nora (1993) constata que há, no século XX, uma aceleração da história, constituída por um momento no qual existe um passado morto e esquecido, e uma ruptura de equilíbrio, em que a memória esfacelada desperta a necessidade de locais de 
memória. Segundo o autor, se antes a memória era resguardada pela sociedadememória, constituída pelos valores e tradições da Igreja, escola, família e Estado, hoje, ela não existe mais. O que encontramos são locais onde a "memória se cristaliza e se refugia" (NORA, 1993, p. 7), onde não existem memórias espontâneas, sendo necessário criar arquivos, comemorar aniversários, e desenvolver espaços para o despertar da memória, já que ela não se compõe mais de forma natural.

É importante ressaltar o fato de Nora utilizar o termo "lugar de memória", inicialmente, para tentar interpretar a onda de cerimônias de rememoração que invadiram a França, no final do século XX, e entender o sentido dos museus, memoriais, bibliotecas e cerimônias em geral, como oficinas da memória da nação, em um ambiente em que a história oficial começava a ser confrontada com muitas outras narrativas. Assim, o conceito foi revisto várias vezes pelo próprio autor e, em seguida, reapropriado por uma infinidade de outros pesquisadores, mas também criticado por alguns por excluir os não-lugares e os não-ditos. Neste trabalho, vamos nos basear na proposição de Nora de que os lugares de memória não se limitam ao que é tangível, mas invadem os espaços do simbólico, para conformar identidades (GONÇALVES, 2012). Dessa forma, vamos considerar as redes sociais e outros espaços on-line, como os blogs, como lugares de memória. A historiadora Rosali Henriques (2014), por exemplo, aponta que o Facebook, além de ser um local de convívio social, é um espaço que registra a memória, preservando-a, mesmo que de forma não intencional. Dessa forma, esses rastros transformaram essa rede social em um "lugar de memória" e ainda contribuem para a preservação de uma memória social online. Assim, acreditamos que o espaço on-line apresenta grande capacidade de ser um lugar de memória, sendo a memória aqui entendida como:

[...] sempre carregada por grupos vivos e nesse sentido, ela está em permanente evolução, aberta à dialética da lembrança e do esquecimento, inconsciente de suas deformações sucessivas, vulnerável a todos os usos e manipulações, susceptível a longas latências e de repetidas vitalizações. (NORA, 1993, p. 9)

Para Nora (1993), a memória é um fenômeno atual, vivido no presente. Ela é fluida, afetiva, simbólica, múltipla e plural. Ela instala a lembrança, emerge e 
une grupos, pode ser individual ou coletiva, mas sempre se enraíza no concreto. Chartier corrobora esse pensamento, ao definir a memória como um fenômeno coletivo e social, "construído coletivamente e submetido a flutuações, transformações, mudanças constantes" (CHARTIER, 2007, p. 2007).

Ao mesmo tempo, nos deparamos com o conceito de história, que Nora define como a "reconstrução sempre problemática e incompleta do que não existe mais" (NORA, 1993, p. 9). Ela é universal e científica, exigindo sempre análise e discurso crítico. Ela se liga às continuidades temporais, às evoluções e às relações entre os acontecimentos. (NORA, 1993; CHARTIER, 2007). Dessa forma, a história seria o local onde a memória é ancorada.

Nesse sentido, o espaço digital oferece a possibilidade do compartilhamento e arquivamento dessas memórias. Podemos encontrar em blogs, sites, redes sociais e plataformas de vídeos, por exemplo, diversos depoimentos e testemunhos, fotografias, vídeos e outros documentos que são armazenados em rede. Além disso, muitas vezes existe o espaço para que indivíduos possam comentar e discutir sobre aquele determinado arquivo ou fato. Com esse pensamento, recorreremos a Maurice Halbwachs (1990) para explorarmos os conceitos de memória individual e coletiva, que são extremamente importantes para compreendermos as relações de memórias estabelecidas no espaço da web.

A obra "Memória coletiva" foi publicada pela primeira vez em 1950 e Halbwachs trabalhou esses conceitos durante a primeira metade do século XX. Assim, sua pesquisa se baseou em memórias de grupos com um contato mais próximo entre si e alguns críticos comentam que os pensamentos do autor devem estar mais enquadrados no sentido de memória nacional. Porém, recorreremos aos conceitos desse autor, pois acreditamos que as memórias coletivas e individuais podem ser repensadas, primeiramente, no ambiente do Círculo do Livro. Mesmo que não se conhecessem pessoalmente, os sócios do clube experimentaram as mesmas atividades e sensações, criando uma relação de pertencimento ao grupo. O laço que juntava as pessoas no clube do livro era a revista, os vendedores e os próprios livros. Além disso, o espaço on-line e midiático se tornou um local em que as lembranças individuais e coletivas 
podem ser rememoradas e compartilhadas, em que essas memórias são afloradas.

A memória individual seria para Halbwachs (1990) uma memória vivida no quadro pessoal do indivíduo, nossas lembranças pessoais por tudo aquilo que vivemos, experimentamos ou até mesmo acreditamos ser memórias. É uma memória interna e autobiográfica, mas que se apoia na memória coletiva, sem deixar de seguir seu caminho. O pensamento individual me pertenceria e não poderia "ser completamente compreendido por nenhum dos membros desses meios, a não ser por mim. Nesse sentido, ele me pertence e, já no momento em que ele se produz, eu serei tentado a explicá-lo por mim mesmo e só para mim” (HALBWACHS, 1990, p. 48).

Porém, para o pensador, ao mesmo tempo, nossas lembranças sempre serão coletivas, mesmo se forem de acontecimentos que só nós vivemos ou de objetos que apenas nós vimos. Na realidade, nós nunca estamos sós. A memória coletiva seria, assim, aquela formada a partir de memórias individuais, mas não se confundindo com elas. Temos a necessidade de apoiar nossas lembranças sobre a dos outros, para confirmar e ratificar nossas memórias. Necessitamos da memória coletiva para criarmos uma identidade grupal, para pertencermos a um grupo, para encontrarmos um lugar para nós mesmos no passado e no presente. Quando fazemos parte de um grupo e pensamos em comum sobre algum aspecto, permanecemos com esse contato em comum com os indivíduos pertences àquela comunidade, "e continuamos capazes de nos identificar com ele e de confundir nosso passado com o seu" (HALBWACHS, 1990, p. 26).

Mas, para que a memória coletiva seja reconhecida como tal, é necessário que as memórias individuais concordem e tenham pontos de contato, mesmo que cada pessoa tenha um papel diferente no grupo: "cada memória individual é um ponto de vista sobre a memória coletiva, que este ponto de vista muda conforme o lugar que ali ele ocupa, e que este lugar mesmo muda segundo as relações que mantenho com outros meios" (HALBWACHS, 1990, p. 51).

Dessa forma, a memória individual e a memória coletiva não existem uma sem a outra. Elas se complementam, apresentam uma dupla condição. As memórias pessoais do indivíduo não são completas se ele não entrar no grupo; 
enquanto a memória do grupo possui relação com os acontecimentos que constituem o passado do indivíduo. As lembranças coletivas oferecem segurança para as individuais, enquanto as individuais devem vir primeiro, senão a coletiva não tem causa (HALBWACHS, 1990). Se começamos a esquecer, temos o hábito de buscar a lembrança através do conjunto, do grupo, da memória coletiva. Assim, essa memória começa a se renovar, reconfigurando-se, buscando ser completa.

Recorremos às reflexões de Paul Ricoeur (2014) para nos ajudar a refletir ainda mais sobre esses conceitos. Para o pensador francês, a identidade do indivíduo possui relação central com a memória, seja individual ou coletiva, e ela pode se manifestar através de ideologias que são formadas baseadas em uma memória comum fundadora. Existiria, assim, uma disputa para saber quem é o verdadeiro detentor das lembranças: o indivíduo ou o grupo. Utilizando as reflexões de Santo Agostinho, John Locke e Edmund Husserl, Ricouer evoca uma linha de pensamento em que a memória seria única e exclusiva do indivíduo. Em contraponto, mencionando Halbwachs, ele cita outra corrente de pensamento, na qual a memória seria exclusivamente coletiva, pois ela não existiria se o indivíduo não estivesse em grupos. Diante dessa polarização, Ricouer acredita que, entre o "eu", o indivíduo, e o "outro", o coletivo, existe o "próximo". Estes seriam aqueles que compartilham o dia a dia e as lembranças das pessoas, e que estão presentes nos dois momentos principais da vida: o nascimento e a morte.

A memória, assim, poderia também funcionar como uma referência ao passado para manter a coesão dos grupos, como comenta Pollak (1989, p. 9): “o que está em jogo na memória é também o sentido de identidade individual e de grupos”. Para ele, mais do que a memória coletiva, podemos encontrar a "memória enquadrada", utilizando-se do termo de Henry Rousso, que nos oferece um quadro de referências e pontos de referências. Seria uma memória grupal que mantém fronteiras sociais, mas as modifica durante o tempo; que reinterpreta o passado em função das disputas do passado e do futuro; que mantém a identidade do grupo, mas que permita a mudança de forma gradual. Ou seja, uma memória que é transitória, humana, social e que pode ser acometida pelo esquecimento. 


\section{Lembranças e memórias: a web também como lugar de nostalgia}

Existe um outro viés pelo qual pode ser observada a memória grupal ou individual: a afetiva. O pesquisador Mario Bressan Junior (2019) destaca que o sentido emocional também está inserido nesse contexto de lembranças. Muitas vezes, nos recordamos de acontecimentos em que tivemos maior carga afetiva e devemos considerar que as emoções podem se modificar de acordo com as circunstâncias. Respaldando-se nos pensamentos de David Le Breton (2009), Bressan afirma que todas as ações do indivíduo estão tocadas pela afetividade, envolvendo sentimentos e emoções. Ele destaca ainda que "temos sempre uma apropriação de afeto sobre os objetos que nos cercam e que é duradoura, independentemente do tempo" (BRESSAN JUNIOR, 2019, p. 91). Dessa forma, os objetos têm papel crucial em criar um vínculo de afeto, sejam individuais ou coletivos:

A afetividade, segundo Le Breton, consiste na mistura de acontecimentos significativos, tanto de ordem pessoal, quanto coletiva, e que colocamos em prática, originando um sistema de valores e interpretando situações conforme referências morais construídas por nós. (BRESSAN JUNIOR, 2019, p. 93)

Assim, a afetividade pode ser aflorada através das lembranças. Ao termos contato com um grupo, indivíduo, um local ou objeto, podemos não só lembrar dos acontecimentos, mas também temos acesso às emoções constituídas anteriormente. Dessa maneira, para compreendermos a memória afetiva é necessário encontrarmos os elementos que provoquem as emoções, observando os afetos obtidos pelo que vivemos no passado em relação a como nos encontramos atualmente. O pesquisador acredita que "o principal fator que evoca essa afetividade no ato de recordar está na busca por um tempo que não volta mais, trazendo lembranças que podem ser seletivas, boas ou ruins" (BRESSAN JUNIOR, 2019, p. 94). Ou seja, o conceito de nostalgia é um importante elo entre a relação emocional entre o presente e o passado.

A etimologia de "nostalgia" já nos apresenta essa constatação. Como explica a pesquisadora Svetlana Boym (2008; 2017), as raízes da palavra são gregas: nostos, que significa voltar ao lar, e algia, traduzida como anseio. Porém, a palavra aparece pela primeira vez na medicina, no século XVII, como uma 
doença curável que acometia diversos indivíduos que estavam longe de casa, inclusive o soldado em guerra com saudade de seu país de origem.

Assim, segundo a autora, a nostalgia pode ser definida pela saudade de um local que não existe mais, ou quem sabe nunca existiu. Hoje, ela não é vista apenas como saudade de um local, mas como um sentimento aflorado pelo desejo de retornar a momentos passados, pelos mais diversos motivos, incluindo a percepção da aceleração do tempo e da globalização (HUYSSEN, 2009; NORA, 1993).

Boym (2017) se propõe a fazer algumas observações sobre a nostalgia. Primeiramente, a autora destaca que a nostalgia não é anti-moderna, mas contemporânea a essa ideia, pois é o resultado de percepção nova de tempo e espaço, que gera a divisão entre local e global. Além disso, ela aponta que

a nostalgia é um anseio por um lugar, mas na verdade é um anseio por um tempo diferente - o tempo de nossa infância, os ritmos mais lentos de nossos sonhos [...] a nostalgia é uma rebelião contra a ideia moderna de tempo, o tempo da história e do progresso. (BOYM, 2017, p. 154)

Assim, Boym compreende que a nostalgia busca se contrapor à ideia da aceleração da história, no sentido de avanços tecnológicos e do progresso. Por fim, a autora revela que a nostalgia não é exclusivamente retrospectiva, podendo se apresentar prospectiva: "as fantasias sobre o passado, determinadas pelas necessidades do presente, têm um impacto direto na realidade do futuro" (BOYM, 2017, p. 154). A nostalgia se apresenta em uma perspectiva de relações entre o presente e o passado, convergindo as relações entre as biografias de pessoas e aquelas de grupos e nações, ou seja, entre memórias individuais e coletivas. E ela pode ser de dois tipos básicos: restauradora ou reflexiva.

De forma resumida, a nostalgia restauradora "não se percebe como nostalgia, mas antes como verdade e tradição" (BOYM, 2017, p. 159). Ela se constitui em uma narrativa principal, o retorno às origens, trazendo temas como família, natureza, pátria, tradição e verdade. Ela busca um retorno de restauração à harmonia original. Já a nostalgia reflexiva, como o próprio nome já diz, surge com um criticismo maior. Ela observa os detalhes, e não os símbolos, ocupando 
diversos locais e imaginários. É formada por aqueles que sentem prazer com o tempo que passou. Enquanto a primeira foca na "memória nacional baseada em uma única versão da identidade nacional”, na segunda prevalece "a memória social, que consiste em quadros coletivos que marcam, mas não definem, a memória individual" (BOYM, 2017, p. 159).

Já Katharina Niemeyer (2018) acredita que a nostalgia também pode trazer o sentido do desejo de retorno a algo que nunca foi experimentado; pelo arrependimento por algo que nunca aconteceu, mas poderia ter acontecido; ou por um futuro que nunca ocorrerá: “o sentimento nostálgico não é meramente voltado para um retorno a um lugar ou tempo passado, mas também abrange outras temporalidades, como o presente e o futuro, e está frequentemente relacionado às imaginações utópicas sociais ou políticas” (NIEMEYER, 2018, p. 29). Assim, a nostalgia apresenta diversos significados, sendo múltipla, plural: "deve ser rotulada de 'nostalgias' com 's', sustentando a pluralidade de suas formas, expressões e significados" (NIEMEYER, 2018, p. 29).

Nesse sentido, Niemeyer (2018) acredita que, para compreendermos a nostalgia, é necessário observar as práticas comunicativas, onde ela se materializa, e as conexões que ela mantém com as tecnologias de mídia e texto. Já Boym (2017) destaca o "boom da nostalgia”, desencadeado pela aceleração das novas tecnologias:

A tecnologia e a nostalgia tornaram-se codependentes [...] a nossa fixação com o ciberespaço e pela aldeia global virtual, há uma epidemia global de nostalgia, e um anseio eletivo por uma comunidade, uma memória coletiva, um desejo de continuidade em um mundo fragmentado. (BOYM, 2017, p. 156)

Assim, o espaço virtual é essencial para que a nostalgia emerja em um contexto de memória individual e coletiva. Como destacam os pesquisadores Bruno Souza Leal, Felipe Borges e Igor Lage (2019), hoje não somos mais apenas atingidos pela nostalgia - ao nos depararmos com filmes, livros, séries, fotografias -, mas somos também fabricantes de narrativas e memórias nostálgicas. 
Dessa forma, gostaríamos de pensar em um novo conceito para os espaços em que são afloradas e construídas nostalgias a partir de lembranças e sentimentos, do compartilhamento de memórias e de saudade. Nesta pesquisa, iremos cunhar o termo "lugar de nostalgia", pensando nos locais onde é possível relembrar, desenvolver e partilhar narrativas nostálgicas e afetivas de forma coletiva. Esses lugares podem ser lugares físicos, como também ambientes virtuais, onde - através de textos, vídeos, áudios e outras mídias - as memórias e os sentimentos nostálgicos ficam ali expostos e conservados, gerando debates, para não serem mais esquecidos.

Nesse contexto, recorremos a Manuel Castells para nos ajudar a compreender como as novas tecnologias estão modificando a organização da sociedade. Para o autor, "em um mundo de fluxos globais de riquezas, poder e imagem, a busca da identidade, coletiva ou individual, atribuída ou construída, torna-se a fonte básica de significado social” (CASTELLS, 2012, p. 41). A comunicação entre os seres humanos e seu relacionamento com a natureza levando em conta a produção, consumo, experiência e poder - se consolidam em territórios característicos e geram culturas e identidades coletivas. Por isso, a tecnologia deve ser entendida, observando sua complexa interação com os indivíduos e instituições. Assim, na contemporaneidade, verificamos que cada vez mais as novas mídias criam espaços de interação. As redes sociais, blogs, aplicativos de mensagens e outros aparatos tecnológicos modificam cotidianamente a interação social humana. E isso também se reflete em como as memórias são construídas e compartilhadas.

Complementando esse pensamento, Henry Jenkins, Joshua Green e Sam Ford (2015) acreditam que as novas plataformas digitais intensificaram a relação comunitária dos indivíduos na criação de conteúdos grupais e colaborativos. Para os autores, as modificações que percebemos da radiodifusão para o digital diminuíram o controle corporativo sobre diversos tipos de conteúdo, gerando uma circulação maior de materiais pensados por usuários, sob novos pontos de vista. Hoje podemos consumir e produzir conteúdos de diversas maneiras através de textos, vídeos, áudios - em uma linguagem híbrida. Em contrapartida, não podemos esquecer, como ressalta exaustivamente Castellls, que nem todas 
as pessoas têm acesso às tecnologias e ao letramento digital, além do que, ainda vivemos sob a luz de restrições corporativas, no âmbito do acesso às redes e aos seus usos.

Já em uma perspectiva histórica, o pesquisador uruguaio Juan Andrés Bresciano (2010) acredita que as transformações tecnológicas, a partir da segunda metade do século XX, modificaram a vida individual e coletiva, originando novos modos de registrar, comunicar e investigar as ações humanas. Como consequência, a forma como o historiador trabalha também foi modificada, seja em uma perspectiva teórica, metodológica ou técnica. Para ele, "as tecnologías recientes amplían el concepto de fuente histórica a través del desarrollo de nuevas clases de registros, soportes y formatos asociados a la cultura digital" (BRESCIANO, 2010, p. 121). Assim, o trabalho de campo do historiador se diversificou e se enriqueceu a partir dos registros obtidos através dos dispositivos eletrônicos. Ao mesmo tempo, é necessário que o pesquisador reflita criticamente sobre a autenticidade das fontes, dentro de uma análise heurística digital.

Para o historiador, os sites da internet podem produzir fontes históricas, que podem ser categorizadas em comerciais, empresariais, institucionais etc. Destacamos nesse trabalho dois tipos, em que acreditamos que podem ser enquadrados os blogs que aqui serão estudados: os sites pessoais, que oferecem dados de uma pessoa a serviço de uma comunidade, e os sites comunitários, que se tornam âmbitos de socialização para pessoas que possuem interesses em comum: "su utilización resulta imprescindible para cualquier historiador que intente comprender los mecanismos y las dinámicas de las formas actuales de interacción microsocial" (BRESCIANO, 2010, p. 21).

No interior desse complexo mundo digital, a grande ferramenta global que contribui no despertar da memória nostálgica, seja ela coletiva ou individual, e nos ajuda a encontrar as fontes historiográficas, é o Google. Em uma análise crítica, Carlo Ginzburg (2012) comenta que Roger Chartier, ao mesmo tempo em que vê um potencial democrático para os rastros da história na internet, como já comentamos, acredita que o Google oferece uma dupla perda no sentido histórico e da memória. Primeiramente, a ferramenta levaria a uma leitura 
fragmentada, que isola pedaços de textos, frases e palavras. Depois, o Google apagaria a especificidade do meio em que os textos sempre foram registrados, transferindo-os para uma mídia, a tela do computador, assim, ocorrendo a perda da especificidade material.

Porém, Ginzburg ressalta que nem sempre essa ferramenta de busca apresenta esse potencial tão negativo. Afinal, o “Google nos ajuda a rastrear uma palavra até um texto que talvez nunca tenhamos lido e de cuja existência nem sequer saibamos" (GINZBURG, 2012). E completa, ao afirmar que instrumentos para operações de busca, como o Google, existem há muito tempo, mas em outras materialidades. Ele oferece como exemplo os índices presentes na bíblia, que permitiam o encontro de fragmentos e citações de forma mais rápida e prática. Segundo ele, a bíblia é um livro que pode ser usado ao invés de ser lido, assim como o Google.

Para o pesquisador, um tipo de leitura não exclui outras, sendo que cada um de nós as alterna, não só dependendo do texto, mas mesmo dentro do texto em si. O Google seria uma extensão, uma prótese do nosso corpo e da nossa mente, que permite que possamos conhecer mais sobre o nosso passado: "a internet hoje atinge um potencial que firma suas raízes em um passado muito remoto"(GINZBURG, 2012). Essa ferramenta de busca seria um poderoso instrumento de pesquisa histórica, mas, ao mesmo tempo, um instrumento de cancelamento da história. Afinal, "no presente eletrônico, o passado se dissolve" (GINZBURG, 2012). Essa contradição, segundo o autor, está modificando o mundo em que vivemos e terá reflexos nas futuras gerações, pois os conceitos e perspectivas de passado, presente e futuro estão cada vez mais frágeis.

Dessa forma, segundo Ginzburg, é necessário realizar uma análise dos materiais empíricos do Google, ou seja, promover estudos de caso para comprovar o potencial da história, e, aqui, incluímos em nossa perspectiva a questão da memória e da nostalgia, no meio digital. Assim, nos propomos a realizar uma Análise de Conteúdo buscando os rastros de memória do Círculo do Livro através dessa plataforma. 


\section{Análise das memórias do Círculo do Livro no Google}

Para realizar a nossa análise, utilizaremos a metodologia de Análise de Conteúdo (AC) de Laurence Bardin (2011). Essa análise tem como principal objetivo encontrar os sentidos ocultos de uma mensagem, decodificando-a para que possamos compreender melhor o conteúdo. Sua principal característica é observar tantos dados quantitativos, como qualitativos, para a melhor entendimento do objeto a ser analisado.

Em nosso caso, utilizaremos a AC para compreender quais as memórias do Círculo do Livro na internet, analisando um conteúdo textual. A metodologia é dividida em três etapas. A primeira, é a pré-analise, quando realizamos uma leitura flutuante no texto para que seja possível observar hipóteses ou questões norteadoras para o trabalho. A partir dessa leitura, elencamos um corpus para a análise. Depois, passamos para a segunda etapa, em que elaboramos índices e indicadores. Um índice pode ser a referência de algum tema na mensagem do documento. A frequência de um determinado índice formará um indicador, que é numérico.

[...] o índice pode ser a menção explícita de um tema em uma mensagem. Caso parta do princípio de que este tema possui tanto mais importância para um locutor quanto mais frequentemente é repetido (caso da análise sistemática quantitativa), o indicador correspondente será a frequência desde tema de maneira relativa ou absoluta, relativo aos outros. [...] Quanto mais escolhidos os índices, procede-se a construção dos indicadores precisos e seguros. (BARDIN, 2011, p. 130)

Dessa forma, a partir do registro de indicadores numéricos, podemos concretizar unidades de categorização, ou categorias, que expressarão os sentidos do texto.

Após o recorte, realizamos a codificação do texto, escolhendo unidades de registro e unidades de contexto. A unidade de registro é o menor recorte de ordem semântica que se libera no corpus do estudo, ou seja, a palavra, expressão ou uma frase ou um conjunto delas que formem um tema ou um sentido. Já a unidade de contexto deve fazer compreender a unidade de registro, como a frase ou um parágrafo onde a unidade de contexto está inserida. Depois de codificarmos, realizamos a enumeração, contando as unidades de registro, e 
classificamos ou a agregamos esses resultados em categorias. Após a exploração do material, obteremos uma tabela completa com as categorias e os índices.

Na terceira etapa, iremos analisar os resultados brutos e interpretá-los de forma qualitativa, a partir da base teórica que consolidamos para desenvolver esta pesquisa.

Assim, primeiramente, iremos realizar uma análise dos resultados da palavra-chave Círculo do Livro no Google, para termos uma visão ampliada dos resultados. Escolhemos o Google para nossa pesquisa pois ele é o site de busca mais utilizado no mundo1. Através da ferramenta de marketing digital Ubersuggest foi possível encontrar qual a busca mensal dessa palavra-chave no Google: 880. Entre outras palavras-chave relacionadas, encontra-se: "círculo do livro editora", com 40 buscas mensais, e "círculo do livro anos 80", "coleção Monteiro Lobato círculo do livro", "círculo do livro catálogo" e "círculo do livro online", todas elas com 20 buscas mensais cada².

Ao buscarmos a palavra-chave Círculo do Livro no Google, tivemos um total de cerca de 37.100.000 respostas. É primordial ressaltar o Google possui um algoritmo de busca próprio - que se utiliza de padrões de relevância, qualidade, entre outros - para classificar a ordem dos conteúdos que serão exibidos para o usuário ${ }^{3}$. Dessa forma, a pesquisa foi realizada em uma aba anônima do navegador, procurando minimizar ao máximo a influência das autoras nos resultados.

Para que fosse possível realizar a análise, definimos como nosso corpus o resultado das primeiras cinco páginas. Assim, obtivemos um total de 55 resultados de busca, excluindo os anúncios de publicidade, que se repetiram. Destacamos que toda a análise foi realizada entre os dias 15 e 17 de maio de 2021.

\footnotetext{
1 Segundo dados recentes da empresa StatCounter GlobalStats, o Google é o site de busca escolhido por 92,24 \% dos usuários da internet. Disponível em https://gs.statcounter.com/search-engine-market-share. Acesso em: 28/05/2021.

2 Disponível em https://app.neilpatel.com/pt/ubersuggest/keyword ideas?keyword=C\%C3\%ADrculo\%20do\%20 Livro\&locld=2076\&lang=pt. Acesso: 15/05/2021

${ }^{3}$ Disponível em: https://www.google.com/intl/pt-BR/search/howsearchworks/algorithms/. Acesso em 28/05/2021.
} 
Após a leitura flutuante, decidimos classificar os resultamos em cinco categorias. A primeira é "Memórias do Círculo do Livro", para sites, blogs e vídeos que fizessem referência à história do clube, com memórias e lembranças. A segunda categoria é "Vendas", para páginas de sites de revenda dos livros do Círculo, a terceira é "Anúncios", englobando anúncios publicitários pagos do Google. A quarta categoria é "Livros do Círculo do Livro", para páginas com conteúdos resenhísticos ou que catalogam as obras, sem fins lucrativos. Por fim, a categoria "Outros" englobou resultados que não fazem referência direta à empresa Círculo do Livro aqui estudado. Como resultado, elaboramos a seguinte tabela:

Tabela 1: Análise quantitativa dos resultados do Google

\begin{tabular}{|c|c|}
\hline Categoria & Resultados \\
\hline Memórias do Círculo do Livro & 11 \\
\hline Vendas & 25 \\
\hline Anúncios & 7 \\
\hline Livros do Círculo do Livro & 3 \\
\hline Outros & 9 \\
\hline Total & 55 \\
\hline
\end{tabular}

Fonte: Elaborado pelas autoras.

Verificamos que 25 resultados, cerca de 45,5\%, estão relacionados à venda de antigos livros do Círculo do Livro. Em segundo lugar, encontramos a categoria "Memórias do Círculo do Livro", que é composta por 11 resultados, 20\% do total. Em terceiro, a categoria "Outros", com nove resultados, ou 16,3\%. Segue a categoria "Anúncios", com sete resultados, 12,8\%, e "Livros do Círculo do Livro", com três resultados, 5,4\%.

Após esse levantamento, desejamos nos aprofundar na categoria "Memórias do Círculo do Livro" para atingir o objetivo desta pesquisa. Foram 11 resultados, compostos por dez conteúdos textuais e um vídeo. Como pretendemos estudar apenas o conteúdo textual, excluímos dessa análise metodológica o vídeo "Minha coleção de livros da CíRCULO DO LIVRO - YouTube”. Os dez resultados restantes textuais são: "Círculo do Livro - Wikipédia, a enciclopédia livre", "A história de um clube do livro com 800 mil sócios", "9 coisas 
que deixarão qualquer leitor nostálgico", "Círculo do Livro: um período que deixou saudades", "Círculo do Livro - Marcelo Moutinho", "Círculo do livro |Planneta Educação", "Livro de papel - Nos tempos do Círculo do Livro”, "Círculo do Livro | Enciclopédia Itaú Cultural", "Círculo do Livro | Livros só mudam pessoas" e "Círculo do Livro - Gazeta do Povo".

Para a segunda etapa, iremos realizar uma nova análise quantitativa. Fizemos um novo recorte, já que desejamos analisar os textos e, posteriormente, os comentários de internautas sobre o Círculo do Livro. Por isso, selecionamos apenas os quatro textos que tratavam exclusivamente do clube e que apresentavam comentários. São eles: "A história de um clube do livro com 800 mil sócios", Texto 1, com 77 comentários; "Círculo do Livro: um período que deixou saudades", Texto 2, com 118 comentários; "Círculo do Livro - Marcelo Moutinho", Texto 3, com 1 comentário; e "Livro de papel - Nos tempos do Círculo do Livro - Posfácio", Texto 4, com 26 comentários.

Primeiramente, iremos analisar o texto desses artigos para compreendermos como a memória do Círculo é narrada por quatro diferentes pessoas.

\section{As memórias compartilhadas do Círculo do Livro em sites e blogs}

O Texto 1, "A história de um clube do livro com 800 mil sócios", foi publicada no site Publishnews em 7 de dezembro de 2012. Escrito por Roney Cytrynowicz, o artigo relata um pouco da história do Círculo do Livro a partir de informações contidas no livro "O Livro no Brasil: Sua História”, de Laurence Hallewell. Roney começa o artigo introduzindo o clube para seus leitores e comentando sobre a importância do livro de Hallewell para a história editorial brasileira, já que poucas publicações se debruçaram sobre esse tema historicamente. Ele também elogia a qualidade dos livros do Círculo, destaca a revista do livro e faz outros comentários:

Os livros eram muito bem acabados graficamente, com capa dura e ótimo design; havia opções realmente para todos os gostos e sempre novidades em todas as seções da revista, inclusive lançamentos em parceria com outras editoras, e a revista era bem produzida e com boas resenhas dos livros. (CYTRYNOWICZ, 2012) 
E ele continua o texto comentando sobre a sua experiência pessoal com o Círculo:

Tenho memórias muito precisas dos anos 1970, de adolescência, quando meu irmão era sócio. [...] Eu ficava dias folheando a revista e fazia também as minhas encomendas, em especial livros de espionagem, romances policiais e políticos. A chegada do vendedor, com as encomendas e o novo exemplar da revista, era sempre um acontecimento. (CYTRYNOWICZ, 2012)

Trazendo suas memórias para o presente, Roney comenta que encontrou quatro edições de livros do Círculo, "cujo formato compacto, capa dura e chamativa os torna inconfundiveis" (CYTRYNOWICZ, 2012): "Os Sobreviventes: A Tragédia dos Andes", “Arquipélago", "Conspiração Telefone" e "Mundo Jovem”. Finalizando, o autor expressa o desejo que sejam criados novos clubes, que possam atender aos interessem de quem preza pelo livro de papel.

O Texto 1 aborda um pouco da história do clube e traz lembranças positivas do autor, que rememora a época através dos livros que ainda possui sobre o Círculo. O autor utiliza-se tanto de informações oficiais, como de lembranças pessoais, para reconstruir a memória do clube para os leitores.

Já o Texto 2, "Círculo do Livro: um período que deixou saudades" foi publicado no blog Livros e Opinião, no dia 8 de julho de 2012. O site pertence ao jornalista José Antônio, sendo ele mesmo o autor do texto analisado. Em um artigo repleto de afeto, José Antônio comenta sobre a sua experiência como assinante do Clube do Livro. Ele introduz o texto afirmando que estava limpando a sua estante e que, ao ver os livros do clube, várias memórias retornaram:

Ao espanar os meus queridos 305 livrinhos, percebi que uma grande parte deles pertenceu a áurea fase do Círculo do Livro. Pronto! Bastou ver algumas dessas capas para me lembrar do período em que fiquei sócio do Círculo e, então, passei a receber pelo correio um catálogo com várias opções literárias, a maioria romances, à preços módicos. (JOSÉ ANTONIO, 2012)

Continuando seu relato, José Antônio comenta outras lembranças do Círculo em sua vida e em sua formação como leitor, ressaltando a importância dessa época para quem ama literatura: "E se você, que lê esse post agora, é tão ou até mais balzaquiano do que eu, também pode bater no peito e gritar: 'Eu vivi 
a época de ouro da literatura romanceada!"” (JOSÉ ANTONIO, 2012). A seguir, ele comenta um pouco sobre a história do clube, resultado, como ele mesmo afirma, de uma pesquisa na internet. Ele relata que não conseguiu encontrar nenhuma informação sobre o motivo do clube ter sido encerrado:

Confesso que passei horas e mais horas "grudado" na tela do computador, fuçando e fuçando em sites e mais sites tentando descobrir os motivos que levaram a Círculo do Livro a decretar falência. [...] Na realidade, os verdadeiros motivos que levaram a suspensão das atividades da Círculo do Livro continuam sendo um verdadeiro mistério. (JOSÉ ANTONIO, 2012)

Finalizando o texto, José Antônio reafirma a importância do Círculo para o mercado brasileiro e confessa sentir saudade.

Esse artigo é o mais saudosista dos quatro textos. José Antônio reforça um sentimento de nostalgia e saudade, que o faz buscar a história do Círculo e compartilhar com seus leitores. Interessante ressaltar que José Antônio escreve diversos comentários no próprio artigo, respondendo às lembranças e aos questionamentos de seus leitores. Entre as conversas, encontramos comentários, que completam o artigo. Na seção de comentários, o usuário Atas complementa algumas informações de datas, e fala da Revista do Livro, publicação enviada pelo Círculo, para que seus leitores escolhessem as obras que desejavam comprar. Por fim, ele ressalta:

Sei que já escrevi demais, mas como já mencionei tenho as revistas. Pensei em digitalizar algo, como a página do editorial, a tiragem, algum livro com sinopse. Isso porque há tão pouca informação a respeito. Mas não sei como enviar, e muito menos se isso cabe aqui na proposta do blog. (ATAS, 2021)

Dessa forma, percebemos como o espaço do blog se torna um local em que as memórias e nostalgias são compartilhadas e disseminadas. $O$ fruto desse compartilhamento de lembranças é outro artigo, publicado em 16 de fevereiro de 2019, intitulado de: "Revista Do Livro: a história de uma revistinha famosa que marcou gerações de leitores"”, no qual José Antônio utiliza-se das revistas de Atas para contar um pouco mais da experiência de assinar o Círculo do Livro.

\footnotetext{
4 Disponível em: https://www.livroseopiniao.com.br/2019/02/revista-do-livro-historia-deuma.html. Acesso em 18 de maio de 2021.
} 
O Texto 3, intitulado "Círculo do Livro" foi publicado no blog Marcelo Moutinho no dia 13 de setembro de 2013. Escrito pelo próprio blogueiro, o texto relata as memórias do Círculo de diversas pessoas que estavam reunidas em um bar em São Paulo:

O chope comia solto no Genial, bar da Vila Madalena, quando o Marcelino Freire nos disse: "Assim que cheguei em São Paulo, o que eu queria mesmo era trabalhar de revisor no Círculo do Livro”. Foi uma daquelas frases que servem como anzol e pescam lembranças remotas, soterradas pelo passar dos anos. (MOUTINHO, 2013)

A partir dessa frase, Moutinho comenta de outras memórias que foram despertadas sobre o Círculo, como questões sobre o funcionamento do clube, os livros que existiam em seu catálogo e lembranças mais pessoais e subjetivas, como o dia em que sua irmã, Sandra, leu o livro "Flicts", de Ziraldo: "Uma publicação do Círculo. Minha irmã já se foi, não tenho ideia de onde o livro, que era dela, foi parar, e nunca mais encontrei aquela edição. Mas fora das páginas as cores não esmaeceram. São minha lembrança mais feliz da Sandra" (MOUTINHO, 2013).

Ele também comenta as lembranças que foram evocadas em seus amigos, Marcelino e Juliana. Finaliza comentando sobre a importância do clube na vida de todos: "Foi por intermédio de seus livros que eu - assim como o Marcelino, a Ju e tantos outros - comecei a perceber que a vida podia ser maior do que a casa dos meus pais" (MOUTINHO, 2021).

Diferente dos outros três textos, esse artigo traz lembranças de mais de uma pessoa, já que o autor narra também as memórias de seus amigos, e destaca uma lembrança muito pessoal em relação a sua família e que está relacionada ao Círculo. Outro ponto que o difere dos outros textos é apresentar apenas um comentário.

O Texto 4 foi publicado no dia 20 de setembro de 2011 no blog Posfácio. Escrito por Lucas Deschain, “Livro de papel - Nos tempos do Círculo do Livro "é um artigo que oferece um panorama do que foi esse clube do livro. O interesse de Deschain em encontrar livros de sebos e coleções fez ele se deparar e conhecer o Círculo do Livro: “Em minha vida bibliófila de 'traça de sebo' (já ouvi 
também a expressão 'rato de sebo') me deparei inúmeras vezes com as edições do Círculo do Livro" (DESCHAIN, 2011).

A partir desse ponto, o autor fornece algumas informações sobre o Círculo, que encontrou na internet, e apresenta algumas capas de livros, finalizando: "Quem sabe algum dia não poderemos ter uma iniciativa parecida com essa para deixar os leitores brasileiros com água na boca... Enquanto isso não acontece, vou continuar escarafunchando as prateleiras dos sebos, tanto os reais quanto os virtuais" (DESCHAIN, 2011).

O Texto 4 é o que mais se diferencia dos outros três artigos, pois traz narrativas memorialísticas e históricas de alguém que parece não ter vivido aquele momento específico. Ele chega a comentar sobre a vontade de ter participado do clube ao expressar o desejo de que surja um projeto parecido. Assim como José Antônio, ele também participa do debate nos comentários.

Através desses quatro textos, podemos perceber como cada um dos deles oferece narrativas de memórias abordando contextos e aspectos diferenciados sobre o Círculo do Livro. Agora, após observamos os textos, nos debruçaremos na análise dos comentários. Foram colhidos todos os 222 comentários a partir dos quatro textos, sendo eles classificados em sete categorias diferentes. A primeira, "Saudade do Círculo do Livro", é composta por comentários que expressam explicitamente saudade do clube, que sugerem boas experiências com o clube e trazem elogios e expressões positivas referentes àquela época; a segunda é "Melancolia", que utilizamos para classificar comentários que expressam pesar pelo encerramento do clube; em "Desejo de Retorno" foram classificados comentários que evocam um desejo de retorno do clube ou que questionam sobre a existência de clubes atuais; em "Recordações de Livros", incluímos comentários que destacam a memória de obras vendidas pelo Círculo, como os livros da Agatha Christie ou do Monteiro Lobato, por exemplo; em "Comentários de Não-Assinantes", encontramos jovens que expressam o desejo de conhecer o Círculo; em "Comentários Objetivos", encontram-se aqueles comentários que buscam relembrar questões específicas do Círculo, como o preço dos livros ou a correta data de encerramento do clube; e, por fim, em "Comentários Excluídos e Outros", incluímos os comentários que fogem do tema 
ou que foram excluídos pelo usuário. Abaixo, na Tabela 2, é possível verificar os resultados da análise:

Tabela 2: Análise quantitativa dos comentários

\begin{tabular}{|l|c|c|c|c|c|}
\hline Categorias & Texto 1 & Texto 2 & Texto 3 & Texto 4 & Total \\
\hline Saudade do Círculo do Livro & 28 & 43 & 0 & 5 & 76 \\
\hline Melancolia & 12 & 10 & 0 & 2 & 24 \\
\hline Desejo de retorno do Clube & 13 & 23 & 1 & 0 & 37 \\
\hline Recordações de livros & 15 & 22 & 0 & 5 & 42 \\
\hline Comentários objetivos & 3 & 11 & 0 & 12 & 26 \\
\hline $\begin{array}{l}\text { Comentários de não- } \\
\text { assinantes }\end{array}$ & 1 & 5 & 0 & 2 & 8 \\
\hline $\begin{array}{l}\text { Comentários excluídos e } \\
\text { outros }\end{array}$ & 5 & 4 & 0 & 0 & 9 \\
\hline Total & 77 & 118 & 1 & 26 & 222 \\
\hline
\end{tabular}

Fonte: Elaborado pelas autoras.

Sinalizamos que, muitas vezes, um mesmo comentário poderia ser classificado em mais de uma categoria. Porém, procuramos categorizá-lo verificando as unidades de contexto e observando qual o maior sentido expresso por ele.

Percebemos que os comentários muitas vezes refletiram os sentimentos e afetos dos artigos. Nos Textos 1 e 2, as categorias que mais se destacaram foram "Saudade do Círculo do Livro" e "Recordações de Livros"; no texto 3, existiu apenas um comentário, na categoria "Desejo de retorno do Clube"; e, por fim, o Texto 4 teve mais comentários classificados como "Comentários Objetivos", "Recordações de Livros" e "Saudade do Círculo do Livro", esses dois últimos empatados.

Agora, seguiremos para a última etapa: a análise qualitativa do conteúdo dos comentários, que nos permitirá observar as narrativas de memórias presentes nesses depoimentos. Acreditamos que é o compartilhamento de afetos, lembranças, memórias, dúvidas e curiosidades nos comentários que tornaram esses espaços on-line lugares de nostalgia. Assim, nossa proposta é analisar qualitativamente cada uma das categorias, pois, dessa forma, poderemos compreender melhor quais os sentidos ali expressos. 
A primeira categoria "Saudades do Círculo do Livro" teve um total de 76 comentários. Observamos que a maioria expressa saudosismo e nostalgia de um tempo que não volta mais, apresentando expressões como "saudade" e "sinto falta”.

Participei como associada do Círculo do livro durante minha adolescência nos anos 70, e confesso que os vários livros que li, ou melhor as viagens que fiz através dos livros me ajudaram a superar os momentos de desânimo e depressão pelos quais passei. Saudade e gratidão!! (OLIVEIRA, 2019)

Outros se expressam através das palavras "bons tempos" ou "boa época", manifestando uma saudade de um tempo no qual tiveram boas experiências:

Deixou saudades, sim... Outro dia comentava com um amigo sobre as publicações do Círculo do Livro. Eu era sócia, ele também era... E era exatamente assim, um "frisson" quando chegava em casa o catálogo. Li dezenas e dezenas de livros através desse sistema. E me lembro de tantas tardes, no meu quarto, adolescente entre 13 e 17 anos, totalmente envolvida nos livros que adquiria. Bons tempos, me lembro disso e por isso sou muito feliz, a leitura é uma viagem fantástica!!! (DOMINGUES, 2014)

Além disso, encontramos nessa categoria comentários saudosistas mais positivos, com expressões como "era tudo muito bom" ou "maravilhoso". São comentários que refletem lembranças felizes e animadas relacionadas ao Círculo, incluindo elogios aos livros, ao preço e ao funcionamento do clube:

[...] Era com ansiedade que eu esperava pela revista (catálogo) trimestral, onde se escolhia os livros que seriam enviados pelo correio! Haviam promoções, alguns selos que vinham junto com os livros e que vc colecionava e trocava por outros livros, edições extras da revista com preços promocionais...[...] As edições eram incriveis! As capas, havia algumas bem bregas, seguiam mais ou menos a breguice do autor... Mas a edição dos clássicos (principalmente) era bem caprichada [...] (DANIEL, 2012)

Na categoria "Melancolia”, com 24 comentários no total, incluímos aqueles que expressam pesar e tristeza com o encerramento do Círculo, com expressões como "pena que acabou" ou "não deveria ter acabado". Esses depoimentos apresentam um sentimento melancólico pelo fim do clube: "Fui sócia por muitos anos. Fã incondicional do Círculo do Livro. Sempre aguardava, ansiosamente, trimestralmente, a chegada da minha encomenda e revista do trimestre seguinte. 
Não deveria ter acabado nunca!" (PEDROSA, 2017) e “[...] Mas sempre amei ler... sinto saudades tb... e lamento que meus filhos, hoje também tracinhas devoradoras, não possam ter algo tão legal..." (MILLA, 2019).

Também encontramos depoimentos que expressam o desejo de retorno do Círculo ou de algum projeto parecido, na categoria "Desejo de Retorno do Clube", com 37 comentários. Foram encontradas expressões como "volta Círculo" ou "hoje existe algo parecido?", para ressaltar uma vontade de participar novamente daquele clube: "Eu era sócia e comprava todos os meses vários livros. Ficaria muito feliz se o Círculo do Livro retornasse" (SILVA, 2016).

Nossa próxima categoria, "Recordações de Livros", teve 42 comentários. Foram diversos os depoimentos tecidos sobre livros específicos, destacando saudade ou mesmo o desejo de encontrá-los em sebos e livrarias, atualmente. Seguem dois exemplos: "Eu era criança na época, mas me lembro muito bem. A minha mãe comprava sempre e até hoje eu tenho a coleção do Monteiro Lobato e os escoteiros mirins [...]" (VIVIANE, 2017) e

[...] Lembro que houve ainda várias edições com capa marrom com detalhes em dourado com livros de Frederick Forsyth, John Le Carré, Clive Cussler, e também capas mais coloridas e com o detalhe do selo na lombada - dessa "safra" tenho dois do Tom Clancy ("Perigo Real e Imediato", com Harrison Ford na capa, e "A Soma de Todos os Medos"), mas também tinha Oliver North, Mario Puzo, Sidney Sheldon, entre outros. (TORRES, 2011)

Tivemos oito comentários classificados em "Comentários de NãoAssinantes", nos quais encontramos depoimentos de pessoas que não viveram naquela época, mas conheceram o clube através de outras pessoas e gostariam de ter participado, possuindo afeto por um clube do qual não fizeram parte. 0 exemplo abaixo, que foi escrito pelo autor do Texto 4 na área de comentários, exemplifica bem:

Acho que todo leitor um pouco mais velho tem alguma história com algum exemplar do Círculo do Livro. Mesmo eu, que nasci depois que a iniciativa tinha acabado, através dos sebos conheci e comprei uma porrada de coisas. Como eu disse, as capas são um show à parte, tem de tudo. Não costumo comprar livro pela capa necessariamente, mas tem capas que a gente se afeiçoa mesmo. (DESCHAIN, 2012) 
Foram classificados em "Comentários Objetivos" os 26 comentários que discutissem alguma questão histórica ou sobre o funcionamento do clube. No texto 4, por exemplo, verificamos uma extensa discussão sobre o ano de término do clube, que muitos acreditam ter sido em 1980. Mas um ex-assinante afirma ter a revista do clube de 1998. Por fim, um ex-vendedor aparece e corrobora essa informação, ao afirmar: "Verdade. Eu trabalhei no Círculo do Livro até o primeiro semestre de 1997, quando eles saíram da R. Ministro Rocha Azevedo e foram para o bairro do Jaguaré" (SERGIO, 2016). Também temos exemplos de indivíduos que buscam alguns resquícios de memória do Círculo: "Pessoal, estou procurando as revistas antigas do Círculo do Livro, aquelas que eram distribuídas aos sócios para que os mesmos pudessem escolher os livros de capa dura do bimestre [...]" (BARROS, 2016).

Por fim, a categoria "Comentários Excluídos e Outros" contemplou os comentários que foram excluídos ou que não traziam nenhuma informação relevante sobre o Círculo do Livro. Na maioria das vezes, eram comentários de autores aproveitando o espaço para divulgarem livros de sua autoria.

Percebemos que as três primeiras categorias possuem comentários que recordam de forma saudosista uma época antiga e que faz falta para essas pessoas. O desejo de retornar a esse momento é reforçado pelos vários comentários similares, que vão se complementando e expressam afeto por um clube de livros antigo e por essa determinada época. Alguns também destacam como antes era mais divertido receber os vendedores em casa ou escolher 0 livro através da revista. Como afirma Boym (2017), muitas vezes a nostalgia surge pela necessidade de retornar a um tempo mais calmo e quando as coisas eram mais simples.

Já em "Recordações de Livros" encontramos memórias mais enraizadas na materialidade, já que ex-assinantes relembram dos títulos, capas, cheiros e da experiência de ler determinados livros. Em "Comentários Objetivos", observamos como os vestígios de memória nos fornecem um panorama sobre a trajetória do clube. Através de discussões e questionamentos, lembranças sobre datas e o funcionamento do Círculo foram reveladas por assinantes e vendedores, ou seja, pessoas que contribuíram para a existência desse clube. 
Porém, verificamos, por exemplo, que a data de encerramento do clube é difícil de ser identificada, pois, enquanto o ex-editor e porta voz da história do Círculo, Fernando Nuno, revela que o clube terminou em 1996, um ex-assinante diz possuir uma Revista do Livro de 1998. Assim, não podemos dar como certa nenhuma informação que é revelada por meio das memórias, mas buscar sempre entender que elas são baseadas em lembranças e esquecimentos, entre fatos e fantasias. Assim, devemos apresentar senso crítico ao tratarmos as informações da internet como fonte histórica confiável (GINZBURG, 2012; BRESCIANO, 2010; CHARTIER, 1999).

Por fim, a categoria "Comentários de Não-Assinantes" contempla comentários de usuários que nunca viveram essa época, mas que expressam um desejo de terem vivido. Como afirma Niemeyer (2018), esse tipo de sentimento também pode ser considerado como um tipo de nostalgia.

Gostaríamos de adicionar também que, entre os depoimentos, existem diversos comentários de ex-funcionários, procurando colegas com quem trabalhavam, e foi possível encontrar até mesmo uma mulher buscando um suposto pai, que era vendedor do Círculo. Dessa forma, o espaço digital se tornou um local de referência para todos aqueles que desejam obter alguma informação sobre o clube.

\section{Considerações finais}

O Círculo do Livro foi um importante clube de assinaturas de livros no Brasil e até hoje faz parte da história editorial do país, mesmo sem haver muitas informações oficiais sobre sua existência. Ainda assim, é perceptível que os próprios ex-assinantes e ex-vendedores se atentaram para a falta de referências históricas oficiais sobre esse clube e, por isso, começaram a compartilhar lembranças e informações, sempre repletas de saudade e afeto.

Acreditamos, dessa maneira, que o espaço virtual apresenta um potencial memorialístico e nostálgico, por permitir o fácil compartilhamento de conteúdo e democratizar o acesso das pessoas às informações e lembranças. As postagens 
sobre o Círculo do Livro comprovam esse papel da web em ser um espaço dinâmico, permitindo que as memórias sejam afloradas e disseminadas.

Através desses quatro textos, os autores conseguiram compartilhar as suas memórias individuais e ainda ofereceram espaços para que outras pessoas também conseguissem compartilhar as suas. Assim, através dessas lembranças coletivas, outras memórias foram despertadas e diversas discussões memorialísticas surgiram, além de debates sobre datas e o funcionamento do clube. Não podemos acreditar em todas as informações que lemos, mas todas as lembranças sobre o clube nos fornecem um panorama sobre como era ser sócio ou funcionário do clube, sobre as lembranças mais recorrentes, de como os livros eram fisicamente, das obras que mais marcaram os leitores, concluindo, dos sentimentos e afetos que até hoje perpetuam a história do Círculo. Nesse aspecto, percebemos que a nostalgia formada nesse contexto pode ser enquadrada como reflexiva, já que é formada por lembranças afetivas, temporais e que se constituem coletivamente.

Dessa forma, a memória coletiva do Círculo do Livro encontrou um espaço onde conseguiu despertar e permanecer, pelo menos até os dias de hoje, em 2021. Afinal, os textos foram publicados em 2011 e 2012, mas ainda são espaços onde podemos compartilhar lembranças e sentimentos. Ao mesmo tempo é possível encontrar entre os comentários informações relevantes sobre o círculo.

Se não podemos encontrar a história desse clube em livros e documentos oficiais, foi necessário construir um "lugar de memória" para que essas lembranças não fossem esquecidas, para que fossem resguardadas e compartilhadas, para que os indivíduos no futuro conheçam o círculo através de depoimentos de pessoas que participaram desse clube. Entretanto, mais do que narrativas de memória, afetos foram compartilhados. Saudade pela época, pesar pelo fim do clube, boas lembranças do Círculo e de seus livros e outros sentimentos podem ser encontrados na maioria dos comentários. E até mesmo quem nunca viveu aquele momento gostaria de ter participado do clube.

Por isso, após essa extensa análise das publicações textuais on-line relacionadas ao Círculo do Livro e seus respectivos comentários, acreditamos que os blogs e sites se apresentam como "lugares de nostalgia" desse clube. 
Afinal, esses espaços permitem que essas lembranças nostálgicas sejam compartilhadas, registradas e armazenadas, para que sempre possamos recorrer a elas em momentos de esquecimento. Tanto os textos, como os comentários, são fontes de informações e sentimentos, inscritos no ambiente on-line, que nos ajudam a compreender o que foi o Círculo do Livro e quais suas implicações históricas nos dias de hoje. São locais onde a história, as memórias e a nostalgia desse clube estão resguardadas e com potencial de criar outras narrativas.

Por fim, gostaríamos de ressaltar que atualmente encontramos diversos clubes de assinatura de livros on-line, sendo que alguns utilizam-se do nome do Círculo para fins publicitários, por exemplo. Eles buscam despertar essa memória nostálgica do clube para conseguir novos assinantes, saudosistas da época. Mesmo trazendo projetos diferenciados, esses novos clubes compreendem a importância que o Círculo do Livro possui na vida de muitos leitores brasileiros.

\section{Referências}

BACEGA, Débora Regina. Através da Tag e o que Alice Encontrou por lá: memória, comunicação e consumo em um clube de livros. Dissertação (Mestrado) Escola Superior de Propaganda e Marketing. Programa de Pós-Graduação em Comunicação e Práticas do Consumo. São Paulo, 2019.

BARDIN, Laurence. Análise de conteúdo. São Paulo: Edições 70, 2011.

BARROS, Edson. Comentário. 2015. In: DESCHAIN, Lucas. Livro de papel - Nos tempos do Círculo do Livro. Posfácio. 2011. Disponível em: https://www.posfacio.com.br/2011/09/20/livro-de-papel-nos-tempos-docirculo-do-livro/. Acesso em: 15 de maio de 2021

BOYM, Svetlana. Mal-estar na nostalgia. História da historiografia, n. 23, p. 153-165, 2017. Disponível em: https://www.historiadahistoriografia.com.br/revista/ article/view/1236. Acesso em 23 abril. 2021.

BOYM, Svetlana. The Future of nostalgia. New York: Basic Books, 2001.

BRESCIANO, Juan Andrés. La historiografía en el amanecer de la cultura digital. Uruguai: Ediciones Cruz del Sur, 2010.

BRESSAN JUNIOR, Mario Abel. Memória teleafetiva. Florianópolis: Insular, 2019.

CASTELLS, Manuel. A sociedade em rede. São Paulo: Paz e Terra. 2012 
CHARTIER, Roger. A aventura do livro: do leitor ao navegador. São Paulo: Editora UNESP, 1999.

CHARTIER, Roger. A história ou a leitura do tempo. Belo Horizonte: Autêntica Editora, 2009.

CYTRYNOWICZ, Roney. A história de um clube do livro com 800 mil sócios. Publishnews. $2012 . \quad$ Disponível em: https://www.publishnews.com.br/materias/2012/12/07/71420-a-historia-de-umclube-do-livro-com-800-mil-socios. Acesso em: 15 de maio de 2021.

DESCHAIN, Lucas. Livro de papel - Nos tempos do Círculo do Livro. Posfácio. 2011. Disponível em: https://www.posfacio.com.br/2011/09/20/livro-de-papelnos-tempos-do-circulo-do-livro/. Acesso em: 15 de maio de 2021.

DOMINGUES, Denise. Comentário. 2014 In: JOSÉ ANTONIO (sem sobrenome). Círculo do Livro: um período que deixou saudades. Livros e Opinião. 2012. Disponível em https://www.livroseopiniao.com.br/2012/07/circulo-do-livro-umperiodo-que-deixou.html. Acesso em: 15 de maio de 2021.

GINZBURG, Carlo. Fronteiras do Pensamento - Carlo Ginzburg - parte II. 2012. 1 vídeo (17:21). Publicado no canal UFRGS TV. Disponível em: https://www.youtube.com/watch?v=xrOxOQ48Wzs\&list=PL489C1D4B7889EFFC\& index=21. Acesso em: 01 maio. 2021.

GINZBURG, Carlo. Fronteiras do Pensamento - Carlo Ginzburg [parte I]. 2012. 1 vídeo (23:08). Publicado no canal UFRGS TV. Disponível em: https://www.youtube.com/watch?v=QKdfsVBP20E. Acesso em: 01 maio. 2021.

GONÇALVES, Janice. Pierre Nora e o tempo presente: entre a memória e o patrimônio cultural. Historiæ, Rio Grande, 3 (3): 27-46, 2012.

HALBWACHS, Maurice. A memória coletiva. Editoria Revista dos tribunais LTDA. Tradução: LairentLépnAchaffter, São Paulo, 1990.

HALLEWELL, Laurence. O livro no Brasil: sua história. 3a edição, 1 reimpressão. São Paulo: Editora da Universidade de São Paulo. 2017.

HENRIQUES, Rosali Maria Nunes. Os rastros digitais e a memória dos jovens nas redes sociais. 2014. Tese (Doutorado em Memória Social). Universidade Federal do Estado do Rio de Janeiro, Centro de Ciências Humanas e Sociais. Disponível em: http://www.memoriasocial.pro.br/documentos/Teses/Tese33.pdf . Acesso em: 28 de maio de 2021.

HUYSSEN, Andreas. Seduzidos pela memória - arquitetura, monumentos, mídia. Rio de Janeiro: Aeroplano, 2000. 
JENKINS, H., GREEN, J., FORD , S. (2015) Cultura da Conexão: criando valor e significado por meio da mídia propagável. São Paulo: Editora ALEPH.

JOSÉ ANTONIO (sem sobrenome). Círculo do Livro: um período que deixou saudades. Livros e Opinião. 2012. Disponível em https://www.livroseopiniao.com.br/2012/07/circulo-do-Livro-um-periodo-quedeixou.html. Acesso em: 15 de maio de 2021.

LEAL, Bruno Souza; BORGES; Felipe; LAGE, Igor. Experiências de nostalgia: de Stranger Things a Vozes de Tchernóbil, diferentes construções nostalgizantes. In: SANTA CRUZ, Lucia; FERRAZ, Talitha (org.) Nostalgias e mídia: no caleidoscópio do tempo. Rio de Janeiro: Ebooks, 2018.

LEE BRETON, David. As paixões ordinárias: antropologia das emoções. Petrópolis, RJ: Vozes, 2019.

MILLA (sem sobrenome). Comentário. 2019. In: JOSÉ ANTONIO (sem sobrenome). Círculo do Livro: um período que deixou saudades. Livros e Opinião.2012. Disponível em https://www.livroseopiniao.com.br/2012/07/circulo-do-livro-umperiodo-que-deixou.html. Acesso em: 15 de maio de 2021.

MOURTINHO, Marcelo. Círculo do Livro. Marcelo Moutinho. 2013. Disponível em http://www.marcelomoutinho.com.br/cronicas/circulo-do-livro. Acesso em: 15 de maio de 2021.

NIEMEYER, Katharina. O poder da nostalgia. In: SANTA CRUZ, Lucia; FERRAZ, Talitha (org.) Nostalgias e mídia: no caleidoscópio do tempo. Rio de Janeiro: Ebooks, 2018.

NORA, Pierre. Entre memória e história: a problemática dos lugares. Projeto História. São Paulo: PUC-SP. $N^{\circ}$ 10, p. 12. 1993. Disponível em https://revistas.pucsp.br/index.php/revph/article/view/12101. Acesso em 1 de abr. de 2021.

NUNO, Fernando. Os mais vendidos do Círculo do Livro. 2021. 1 vídeo (34m47s). Publicado no canal Guia dos curiosos. Disponível em: https://www.youtube.com/watch?v=pYuRzccNhkU. Acesso em: 08 abril de 2020.

OLIVEIRA, Eliane Silva. Comentário. 2019 In: CYTRYNOWICZ, Roney. A história de um clube do livro com 800 mil sócios. Publishnews. 2012. Disponível em: https://www.publishnews.com.br/materias/2012/12/07/71420-a-historia-de-umclube-do-livro-com-800-mil-socios . Acesso em: 15 de maio de 2021.

POLLAK. Michael. Memória, esquecimento, silêncio. Revista Estudos Históricos. Rio de Janeiro: vol. 2, n. 3, 1989. Disponível em http://www.uel.br/cch/cdph/arqtxt/Memoria esquecimento silencio.pdf. Acesso de 1 de abr. de 2021. 
PREDROSA, Marcia. Comentário. 2017. In: CYTRYNOWICZ, Roney. A história de um clube do livro com 800 mil sócios. Publishnews. 2012. Disponível em: https://www.publishnews.com.br/materias/2012/12/07/71420-a-historia-de-umclube-do-livro-com-800-mil-socios . Acesso em: 15 de maio de 2021.

SÉRGIO (sem sobrenome). Comentário. 2016. In: DESCHAIN, Lucas. Livro de papel - Nos tempos do Círculo do Livro. Posfácio. 2011. Disponível em: https://www.posfacio.com.br/2011/09/20/livro-de-papel-nos-tempos-docirculo-do-livro/. Acesso em: 15 de maio de 2021.

SILVA, Rosani da Silva. Comentário. 2015. In: CYTRYNOWICZ, Roney. A história de um clube do livro com 800 mil sócios. Publishnews. 2012. Disponível em: https://www.publishnews.com.br/materias/2012/12/07/71420-a-historia-de-umclube-do-livro-com-800-mil-socios . Acesso em: 15 de maio de 2021.

TORRES, Bruce. Comentário. 2011. In: DESCHAIN, Lucas. Livro de papel - Nos tempos do Círculo do Livro. Posfácio. 2011. Disponível em: https://www.posfacio.com.br/2011/09/20/livro-de-papel-nos-tempos-docirculo-do-livro. Acesso em: 15 de maio de 2021.

VIVIANE (sem sobrenome). Comentário. 2017. In: JOSÉ ANTONIO (sem sobrenome). Círculo do Livro: um período que deixou saudades. Livros e Opinião. 2012. Disponível em https://www.livroseopiniao.com.br/2012/07/circulo-do-Livroum-periodo-que-deixou.html. Acesso em: 15 de maio de 2021.

Universidade do Estado de Santa Catarina - UDESC

Programa de Pós-Graduação em História - PPGH

Revista Tempo e Argumento Volume 13 - Número 34 - Ano 2021 tempoeargumento.faed@udesc.br 